\title{
Prematüre retinopatisinde kardiyak ejeksiyon fraksiyonu ve konjenital kalp hastalıkları
}

\section{Cardiac ejection fraction and congenital hearth diseases in retinopathy of}

\section{prematurity}

\author{
Hüseyin Gümüş1 ${ }^{\mathbb{D}}$, Yasin Özcan² \\ 1 Harran Üniveristesi Tıp Fakültesi, Çocuk Sağlığı ve Hastalıkları Ana Bilim Dalı / Şanlıurfa \\ 2 İstanbul İstinye Devlet Hastanesi, Göz Hastalıkları Kliniği
}

Öz.

Amaç: Prematüre retinopatisi (PR) gelişen ve gelişmeyen olgularda kardiyak ejeksiyon fraksiyonu $(\mathrm{EF})$ ve konjenital kalp hastalıklarının (KKH) incelenmesi.

Materyal ve Metod: Prospektif özellikteki çalışmaya 57 prematüre hasta dahil edildi. PR gelişen 27 olgu Grup 1, PR gelişmeyen 30 olgu Grup 2 olarak sınıflandırıldı. Kardiyak parametreler M-mode ekokardiyografi ile ölçüldü. Veriler SPSS programında analiz edildi.

Bulgular: Grupların Ort. DH'ları arasında anlamlı bir fark gözlenmezken, 1. Gruptaki olguların ort. DA'sının anlamlı olarak düşük olduğu gözlendi ( sırasıyla $p=0.12, p=0.03$ ). 1. Gruptaki olgularda

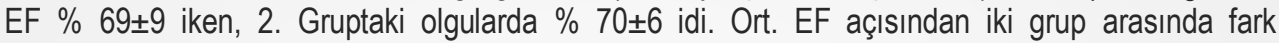
saptanmadı ( $p>0.05$ ). Atrial septal defekt (ASD) görülme sıklığı 1. Grupta \%40,8, 2. Grupta \% 41, patent ductus arteriozus (PDA) sıklığı ise 1. Grupta \% 26., 2. Grupta \% 12.5 idi. Birinci grupta gözlenen PDA sıklığının istatistiksel olarak daha yüksek olduğu gözlendi ( $p<0.05)$.

Sonuç: PR gelişen ve gelişmeyen olgularda EF açısından fark gözlenmezken, PR gelişen olgularda KKH'lardan PDA yaklaşık 2 kat daha sık gözlenmektedir. PR gelişen olgular PDA'nın kapanması için yakından takip edilmelidir.

Anahtar Kelimeler: Prematüre, Retinopati, Kardiyak hastalık

\section{Abstract}

Background: To investigate cardiac ejection fraction measurements and presence of any congenital hearth disease in premature babies with and without retinopathy of prematurity

Method: Totally 57 premature patients enrolled to the study. Twenty-seven patients with ROP defined as Group1 and 30 patients without ROP defined as Group 2. All cardiac parameters were measured by using M-mode echocardiography. Datas analyzed in SPSS programme.

Results: No significant difference was found to be in terms of mean gestational age, whereas the mean GA was significantly lower in Group 1 (respectively $p=0.12, p=0.03$ ). The mean ejection fractions were $69 \pm 9 \%$ in Group 1 and $70 \pm 6 \%$ in Group 2, there was no significant difference in EF between two groups ( $p>0.05$ ). The incidences of ASD were $40.8 \%$ in Group 1 and $41 \%$ in Group 2. The incidences of PDA were $26 \%$ in Group 1 and $12.5 \%$ in Group 2. The incidence of PDA was significantly higher in Group $1(p<0.05)$

Conclusion: There is no significant differences in terms of EF and ASD in patients with and without ROP, while the incidence of PDA was two times higher in patients with ROP. Patients with ROP should be closely followed for closure in PDA.

Keywords: Premature, Retinopathy, Cardiac disease

\section{Sorumlu Yazar I \\ Corresponding Author}

\section{Dr. Hüseyin GÜMÜŞ}

Harran Üniveristesi Tıp Fakültesi Çocuk Sağlığı ve Hastalıkları AD, 63000 Şanlıurfa, Türkiye

Tel: +90 5306376520

E-mail: huseyingumus2163@hotmail.com Geliş tarihi / Received: 01.07.2019 Kabul tarihi / Accepted: 22.07.2019

DOI: 10.35440/hutfd.585133 


\section{Giriş}

Prematüre retinopatisi (PR) tüm dünyada çocukluk çağındaki önlenebilir körlüklerin en önemli nedeni olarak karşımıza çıkmaktadır (1).

Her ne kadar hastalığın patogenezi tam olarak ortaya konamamış olsa da erken doğum, düşük doğum ağırlığı, uzamış yüksek oksijen maruziyeti, sepsis, hipoksi, kan transfüzyonu ve anemi gibi vücutta hemodinamik dengeyi bozan durumların PR gelişimi için birer risk faktörü olduğu belirtilmiştir. PR' nin yaklaşık \%90'ı kendiliğinden gerilerken, $\% 10$ dan az bir kısmı ilerleme göstererek retina dekolmanına ve sonuçta körlüğe neden olmaktadır $(2,3)$. Non-invasiv bir yöntem olan fonksiyonel ekokardiyografinin yenidoğan yoğun bakımlarda artan kullanımı ile preterm bebeklerde konjenital kalp hastalığı ve ventriküler performansı erken dönemde değerlendirme imkanı doğmuş ve tüm konjenital kalp hastalıkları arasından sadece patent duktus arteriozus (PDA)'un PR gelişimi için bir risk faktörü olduğu belirtilmiştir (4-6).

Yaptığımız bu çalışmada PR gelişen ve gelişmeyen olgularda fetal ekokardiyografi yöntemi ile vertriküler performansın bir belirteci olan ejeksiyon fraksiyonlarının karşılaştırıması (EF) ve konjenital kalp hastalıklarının incelenmesi amaçlanmıştır.

\section{Materyal ve Metod}

Bu retrospektif iki merkezli çalışma, Ocak 2018 ile Mart 2019 arasında III. seviye yenidoğan yoğun bakım ünitesinde prematüre retinopatisi (ROP) tanısıyla takip edilen 57 prematüre hasta dahil edildi. Çalışma Harran Üniversitesi Etik Kurulu tarafindan onaylandı (Onay numarası:08.07.2019 tarih, 7 nolu oturum, 29 sayll karar) ve Helsinki Bildirgesi uyarınca yapıldı. Prematüre retinopatisi (PR) gelişen 27 olgu Grup 1, gelişmeyen 30 olgu Grup 2 olarak sınıflandırıldı. Olguların ilk PR taramaları dogumdan sonraki 4. haftada, dogum haftası $<27$ hafta olan olguların ise postnatal 31. haftada yapıldı. Muayene öncesi \%0,5 tropikamid ve $\% 2,5$ fenilefrin damlaları 10 dakika ara ile 2 kez damlatılarak pupilla dilatasyonu saglandı. Topikal anestezi için \%0,5'lik proparakain hidroklorür damla kullanıldıktan sonra pediyatrik kapak spekulumu ve depresör yardımıyla binoküler indirekt oftalmoskop ve 28 diyoptrilik lens kullanılarak PR konusunda deneyimli göz hastalıkları uzmanı tarafından oftalmolojik muayene yapıldı. Tüm bebekler aynı hekimler tarafından muayene edildi. PR evrelemesi ve tanısı uluslararası PR sınıflaması kriterlerine göre yapıldı. PR gelişen olgular hastalığn șiddetine ve evresine göre protokole uygun şekilde belirli aralıklarla tekrar muayene edildi. Kardiyak parametreler Mmode ekokardiyografi ile ölçüldü.

Belirlenen kontrol tarihlerinde düzenli olarak muayeneye gelmeyen hastalar çalışmaya dahil edilmedi.

İstatistiksel analizler SPSS 24.0 versiyon (SPSS Inc, Chicago, IL) paket programı kullanılarak yapıldı. Tanımlayıcı istatistikler sayı, yüzde, ortalama ve standart sapma olarak özetlendi. Değ işkenlerin normal dağılıma uygunluğu görsel (histogram ve olasılık çizelgeleri) ve analitik yöntemler (Kolmogorov-Smirnov) kullanılarak incelenmiştir. Normal dağılımlı verilerin analizi Independent sample $T$ testi ile yapıldı. Normal dağılıma sahip olmayan olguların analizi Mann Whitney U testi kullanılarak yapıldı. Gruplar arasında nitel verilerin karşılaştııılması için ki-kare testi uygulanmıştır. $P$ değeri 0,05 'in altında olan veriler istatistiksel olarak anlamlı sayıldı.

\section{Bulgular}

Ortalama ( ort.) doğum haftası ( DH) 1. Grupta 30.2 \pm 2.4 hf, 2. Grupta $31.0 \pm 1.5$ hafta idi. Ortalama doğum ağırlığı (DA) 1. Grupta $1630 \pm 450$ gram ( gr), 2. Grupta ise $1810 \pm 320$ gram ( gr) idi. Ort. DH'ları arasında anlamlı bir fark gözlenmezken, 1. Gruptaki olguların ort. DA'sının anlamlı olarak düşük olduğu gözlendi ( $p=0.12, p=0.03)$. Ortalama Ejek-

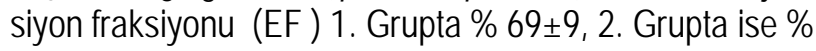
$70 \pm 6$ idi. Ort. EF açısından iki grup arasında anlamlı bir fark saptanmadı ( $p>0.05)$.

Olgulara ait ort. DA, DH, EF ve takip süreleri Tablo 1'de özetlendi.

Tablo 1. Her iki gruptaki olgulara ait ortalama veriler ve bunlara ait $p$ değerleri

\begin{tabular}{lccc}
\cline { 2 - 4 } & $\begin{array}{c}\text { Grup 1 } \\
(\mathrm{n}=27)\end{array}$ & $\begin{array}{c}\text { Grup B } \\
(\mathrm{n}=30)\end{array}$ & p değeri \\
\hline Doğum haftası (DH)/ hafta & $30.2 \pm 2.4 \mathrm{hf}$ & $31.0 \pm 1.5 \mathrm{hf}$ & $\mathrm{p}=0.12$ \\
Doğum ağılığı (DA)/gram & $1630 \pm 450 \mathrm{gr}$ & $1810 \pm 320 \mathrm{gr}$ & $\mathrm{p}<0.05^{\star}$ \\
Ort. Takip süresi / hafta & $17 \pm 3 \mathrm{hf}$ & $15 \pm 5 \mathrm{hf}$ & $\mathrm{p}=0.15$ \\
Ejeksiyon Fraksiyonu/ \% & $\% 69 \pm 9$ & $\% 70 \pm 6$ & $\mathrm{P}=0.35$ \\
\hline
\end{tabular}

Her iki grupta da en sık gözlenen konjenital kalp hastalıkları (KKH) atrial septal defekt ( ASD) ve PDA idi. ASD sıklığı 1. Grupta \% 40.8 , 2. Grupta \% 41, PDA sıklığı ise 1. Grupta \% 26, 2. Grupta \% 12.5 idi. Birinci grupta gözlenen PDA sıkı̆̆ının istatistiksel olarak daha yüksek olduğu gözlendi $(p<0.05)$. Her iki gruptaki Ekokardiyografi bulguları Tablo 2'de özetlendi.

Tablo 2. Her iki gruptaki olgulara ait Ekokardiyografi bulguları ve bunlara ait $p$ değerleri

\begin{tabular}{cccc}
\hline Konjenital Kalp Hastalığı & Grup 1 $(\mathbf{n}=\mathbf{2 7})$ & Grup 2 $(\mathbf{n}=\mathbf{3 0})$ & P değeri \\
\hline ASD & $\% 40.8$ & $41 \%$ & $p>0.05$ \\
PDA & $\% 26.2$ & $\% 12.5$ & $p<0.05$ \\
VSD & $14 \%$ & $17 \%$ & $p>0.05$ \\
\hline
\end{tabular}

\section{Tartışma}

Yaptığımız çalışmada PR gelişen ve gelişmeyen olgularda ventriküler performansın önemli bir göstergesi olan ejeksi- 
yon fraksiyonları arasında anlamlı bir fark olmadığını gözlemledik. Ciccone M ve ark.(7) neonatal ekokardiyografi ile yaptıkları çalışmada prematüre olgularla term olguların EF'leri arasında anlamlı bir fark olmadığını göstermelerine rağmen sol ventrikül boyutlarının prematürelerde anlamlı olarak daha küçük boyutlarda olduğunu bildirmişlerdir. Yine Levy PT ve ark.(8) da prematüre ve term olgular arasında EF açısından anlamlı bir fark bulunmadığını belirtmişlerdir. Çalışmamızda elde ettiğimiz veriler de literatüre ek olarak olguların preterm doğum öyküsüne sahip olmasının EF'yi anlamlı bir şekilde etkilenmediğini ortaya koymuştur.

Bir çok infantta hafif soldan-sağa şantlı patent foramen ovalenin (PFO) varlığı ASD görülme sıklığında artışa neden olmaktadır. ASD ve PFO nun ayrımı için net olarak bir tanı kriteri bulunmamakla beraber $>3 \mathrm{~mm}$ üzerindeki fossa ovalisler ASD olarak isimlendirilmektedir. ASD genellikle asemptomatik olup erken tanı ve ileri tedavi gerektirmeyen ve hemodinamik durumu nadiren etkileyebilen bir $\mathrm{KKH}$ olması nedeni ile PR gelişimi ile ilişkisi olmadığı belirtilmiştir $(9,10)$. Bizde yaptığımız çalışmada en sık KKH'yı ASD olarak saptamamıza rağmen gruplar arasında görülme sıklıklarının benzer olduğunu gözlemledik.

Tüm infantlarda en sık gözlenen $\mathrm{KKH}$, ventriküler septal defekt (VSD) olmasına rağmen yapılan çalışmalarda sadece PDA varlığının Prematüre retinopatisi gelişim patogenezi ile ilişkili olduğu gösterilebilmiş̧ir (11). Hayatın ilk birkac, gününde normal yenidogan be- beklerin üç̧te ikisinde masum ưfürüm duyulur. Yenidogan bebeklerde uifürüm en sık konsuiltasyon nedenidir ve üfürüm dışında klinik bulgusu olmayan yeni-doganlarda yapısal kardiyak anomali sıklı̆ı \%54-86'dır. PDA ise en sık rastlanılan patoloji olarak bildirilmektedir. Unitemizde izlenen bebeklerde en sık kardiyoloji konsuiltasyonu istenme nedeni ufürümdür ve bu bebeklerde DKH sıklığı $\% 63.5$ olarak belirtilmiştir (12-14).

PDA görülme sıklığı gebelik haftası ile ters orantılı olduğu için prematürelerde daha sıklıkla gözlenmektedir. Term bebeklerde PDA insidansı 1000 canlı dogumda 57 iken, çok düşük dogum ağırlıkı (ÇDDA; $<1500 \mathrm{~g})$ prematürelerde $\% 33$ ve așırı düșük dogum ağrlıkı (ADDA; <1000g) prematürelerde ise $\% 65$ oranında görülmektedir (15). Patent duktus arteriozusun hemodinamiyi bozması sonucunda önemli prematüre morbiditeleri olan nekrotizan enterokolit, interventriküler hemoraji ve bronkopulmoned displazi riskini artırdığ bilinmektedir. Hemodinamik anlamlı PDA grubundaki düșük GH ve DA yanında uzamıs, olan solunum ve oksijen destegi nedeni ile PR gelişme riskini artırmaktadır(16). Yaptığımız çalışmada PDA görülme sıklığının PR gelişen hastalarda yaklaşık olarak 2 kat daha fazla gözlendiğini saptadık.

Sonuç olarak elde ettiğimiz verilerle EF'nin doğum öyküsünden etkilenmediği, PDA varlığının PR gelişen olgularda görülme sıklığının daha yüksek olduğu saptayarak; yenidoğan yoğun bakımda erken dönemde yapılacak ekokardiyografinin hemodinamiyi bozan konjenital kalp hastalıklarının belirlenmesi ve buna göre oluşturulacak tedavi ve takip planlarıyla olguların morbidite ve mortalitelerinin azalacağını düşünmekteyiz.

\section{Kaynaklar}

1. Özcan PY. Prematüre Retinopatisinde Etyopatogenez. Güncel Retina 2018; 2:5-12.

2. Darlow BA, Hutchinson JL, Henderson-Smart DJ. Prenatal risk factors for severe retinopathy of prematurity among very preterm infants of the Australian and New Zealand Neonatal Network. Pediatrics 2005; 115: 990-6.

3. Chen $Y, X u n D$, Wang $Y C$, Wang $B$ et al. Incidence and risk factors of retinopathy of prematurity in two neonatal intensive care units in North and South China. Chin Med J (Engl). 2015; 128: 914-8.

4. Breatnach CR, Levy PT, James AT, Franklin O, El-Khuffash A. Novel echo- cardiography methods in the functional assessment of the newborn heart. Neonatology 2016; 110: 248-60.

5. Lewandowski AJ, Bradlow WM, Augustine D, Davis EF et al. Right ventricular systolic dysfunction in young adults born preterm. Circulation 2013; 128: 713-20.

6. Mitsiakos G, Papageorgiou A. Incidence and factors predisposing to retinopathy of prematurity in inborn infants less than 32 weeks of gestation. Hippokratia. 2016 ;20(2):121-6.

7. Ciccone MM, Cortese F, Gesualdo M,Di Mauro A et al. The role of very low birth weight and prematurity on cardiovascular disease risk and on kidney development in children: a pilot study. Minerva Pediatr. 2016. [Epub ahead of print]

8. Levy PT, El-Khuffash A, Patel MD, Breatnach CR et al. Maturational patterns of systolic ventricular deformation mechanics by Two-Dimensional speckle-Tracking echocardiography in preterm infants over the first year of age. J Am Soc Echocardiogr. 2017, 30.7: 68598.

9. Azhari N, Shihata MS, Al-Fatani A. Spontaneous closure of atrial septal defects within the oval fossa. Cardiol Young 2004; 14: 14855.

10. Serafini O, Misuraca G, Greco F, Bisignani G, Manes MT, Venneri N. Prevalence of structural abnormalities of the atrial septum and their association with re- cent ischemic stroke or transient ischemic attack: echocardiographic evaluation in 18631 patients. Ital Heart J Suppl 2003; 4: 39-45

11. Lopez L, Colan SD, Frommelt PC, Ensing GJ et al. Recommendations for quantification methods during the performance of a pediatric echocardiogram: a report from the Pediatric Measurements Writing Group of the American Society of Echocardiography Pediatric and Congenital Heart Disease Council. J Am Soc Echocardiogr 2010; 23: 465-95; quiz 576-7.

12. Azhar AS, Habib HS. Accuracy of initial evaluation of heart murmurs in neonates: Do we need an echocardiogram ?. Pediatr Cardiol. 2006; 27:234- 7.

13. Du ZD, Roguin N, Barak M. Clinical and echocardiyografik evaluation of neonates with heart murrnurs. Acta Pediatr 1997, 86.7: 7526.

14. Güven H, Bakiler AR, Kozan M, Aydınoglu H, Helvacı M, Dorak C. Echocardiographic screening in newborn infants. Cocuk Sağığ ve Hastalıkları Dergisi 2006;49:8-11.

15. Bhat R, Das UG. Management of patent ductus arteriosus in premature infants. Indian J Pediatr 2015; 82(1): 53-60.

16. Halil H, Buyuktiryaki M, Atay FY, Yekta Oncel M, Uras N. Reopening of the ductus arteriosus in preterm infants; Clinical aspects and subsequent consequences. J Neonatal Perinatal Med. 2018; 11(3):273-9 